\title{
A Avaliação da Criatividade nas Organizações: Estudo Comparativo de Técnicas Usuais e Estandardizadas de Avaliação Psicológica
}

\author{
The Evaluation of Creativity in Organizations: Comparative Study of Usual and \\ Standardized Psychological Evaluation Techniques
}

\author{
Karina Nalevaiko da Rocha ${ }^{1}$ e Solange Muglia Wechsler ${ }^{2}$
}

\begin{abstract}
Resumo
As empresas reconhecem a importância da criatividade para o seu negócio e é crescente o interesse em contratar profissionais criativos e inovadores. Este trabalho teve como objetivo comparar a avaliação da criatividade em processos seletivos através da prática mais utilizada pelas empresas, Dinâmica de Grupo, com instrumentos estandardizados de avaliação psicológica. Participaram da pesquisa 54 sujeitos, os instrumentos utilizados foram os Testes de Torrance e Folha de Observação da Dinâmica. Os resultados encontrados demonstram que os critérios avaliados nas empresas (Dinâmica de Grupo) são diferentes dos critérios avaliados nos testes estandardizados de avaliação, mostrando que a prática usual não é eficaz na avaliação da criatividade. Este trabalho demonstra a importância de utilizar-se testes psicológicos validados para garantir a eficácia dos processos seletivos, buscando eximir o quanto for possível aspectos subjetivos na avaliação, evitando assim, uma avaliação baseada apenas na observação e contribuindo para um método de trabalho mais padronizado.
\end{abstract}

Palavras-chave: processo seletivo, avaliação da criatividade, criatividade nas organizações

\begin{abstract}
Companies recognize the importance of creativity for their business and there is a growing interest in hiring creative and innovative professionals. The purpose of this study was to compare the evaluation of creativity in selective processes through the practice most used by companies, Group Dynamics, with standardized psychological evaluation instruments. Participated in the survey 54 subjects, the instruments used were the Torrance Tests and Dynamics Observation Sheet. The results show that the criteria used in the companies (Group Dynamics) are different from the criteria evaluated in the standardized evaluation tests, showing that the usual practice is not effective in the evaluation of creativity. This work demonstrates the importance of using validated psychological tests to guarantee the efficacy of the selective processes, seeking to exempt as far as possible subjective aspects in the evaluation, thus avoiding an evaluation based only on observation and contributing to a more standardized work method.
\end{abstract}

Keywords: selection process, assessment of creativity, creativity in organizations

1 Doutoranda e Mestre em Psicologia pela PUC Campinas e Especialista no Desenvolvimento do Potencial Humano nas Organizações pela PUC Campinas. Pontifícia Universidade Católica de Campinas - SP. Rua Centenário, no 2709 - Bairro Centro. CEP: 83601-000 - Campo Largo PR, Brasil. Tel.: 413392-4579/419565-9139. E-mail: kanalevaiko@gmail.com.br

${ }^{2}$ Phd. Professora da Pós Graduação strictu Sensu da PUC Campinas. 


\section{Introdução}

Atualmente, as empresas estão cada vez mais preocupadas e somando esforços no sentido de serem inovadoras, pois segundo Rodrigues e Veloso (2013) inovar é hoje, um imperativo para as organizações. Para uma empresa se manter competitiva no mercado global, ela necessita de estratégias baseadas em inovações e requer capacidades internas em constantes e intensas transformações (Parolin, 2013). Assim, a magnitude e a velocidade das transformações no mercado exigem decisões rápidas para fatos novos, para os quais não se podem utilizar padrões pré-estabelecidos, havendo a necessidade de criar-se novas alternativas e soluções (Alencar, 1995). Todo esse cenário exige um melhor entendimento do fenômeno da criatividade, pois há uma estreita relação entre inovação e criatividade, mesmo tratando-se de conceitos diferentes.

Mesmo com tantos conceitos, é consenso que a estrutura fundamental do fenômeno criativo são as ideias criativas e quando aplicadas, teriam a capacidade de promover a inovação de estruturas, estratégias e processos organizacionais (Bedani, 2012). Segundo Amabile (1996), toda inovação começa com ideias criativas, pois a implementação bem-sucedida de novos programas, novos produtos ou serviços depende que seus colaboradores tenham uma boa ideia. Assim, a inovação decorre da implementação de ideias criativas (Bruno-Faria, 2003) e seria, portanto, a produção de ações frente à criação de ideias (Petrini, 1998). A criatividade é o desejo de criar, mas que precisa ser transformada em inovação, ou seja, tornando as ideias criativas em produtos, serviços, processos ou métodos operacionais (Parolin, 2008). Assim, a inovação é a implementação eficaz das ideias que provêm da criatividade (Amabile, 1997) evidenciando que a criatividade é uma condição necessária para que a inovação ocorra com sucesso (Marks \& Huzzard, 2008).

Nas empresas, a criatividade é transformada em valor econômico, ou seja, postula-se que a criatividade contribui para a produtividade, competitividade e sobrevivência organizacional (Bendassolli, 2009). Atualmente, onde a regra nas organizações passou a ser a mudança, diferente da concepção de estabilidade citada pelos economistas neoclássicos, a criatividade passa a ter destaque e importância crescente, sendo uma competência desejada, onde as empresas estão buscando-a e empenhando-se a incorporá-la na cultura das empresas (Fonseca \& Bastos, 2003).

A globalização, a competição no mercado de trabalho, o avanço da tecnologia e o ritmo acelerado das mudanças pressionam as empresas a buscarem novos modelos e formas de gestão, exigindo novos posicionamentos de seus colaboradores (Alencar, 1998). Com a rapidez dos avanços tecnológicos as empresas precisam ser flexíveis para manter-se no mercado e evoluírem (Andrade, 2009). Esse ritmo vertiginoso de mudanças está delineando um novo paradigma de gestão de acordo com o qual as organizações deverão ter como principais atributos a velocidade, a flexibilidade, a capacidade de focalização e horizontalidade da estrutura e assim, o que se espera das pessoas no trabalho hoje não é que se esperava há alguns anos atrás (Milaré, 2007). Apenas o conhecimento adquirido na formação universitária não garante empregabilidade ao profissional, mas cada vez mais as empresas buscam pessoas qualificadas para atingir os objetivos estratégicos da empresa, que somem competências essenciais à organização e ganhem competitividade (Dias, 2013). Desta forma, o material mais precioso de uma organização são as pessoas (Chiavenato, 2005), emergindo a conscientização para o valor do capital humano como um diferencial competitivo (Almeida, 2008). Segundo Coelho (2013) a criatividade constitui-se como a competência que determina parâmetros para o sucesso ou fracasso de uma organização, desta forma, identificar e desenvolver a criatividade nas organizações pode ser o grande diferencial no posicionamento de uma empresa no mercado competitivo.

\section{O processo seletivo nas organizações}

Para que as empresas possam suprir às novas demandas, os empresários optam por inovação e recursos humanos mais criativos (Perez, 2005) e buscam na seleção a forma de maximizar o capital intelectual (Pedroso \& Cintra, 2010). O recrutamento e seleção são essenciais à organização e orientam políticas de Recursos 
Humanos, pois nenhuma política de RH será satisfatória se o processo de seleção não o for (Andrade, 2009). A contratação de funcionários em uma empresa, assim como outras atividades, é parte do negócio, que quando bem executadas transformam gastos em lucros (Cappelli, 2010). Em um estudo longitudinal realizado com 750 empresas americanas, Watson Wyatt World Wide no Canadá conclui que investimentos em recrutamento e seleção e retenção de talentos podem aumentar o valor da empresa no mercado (Bates, 2001).

Anteriormente buscava-se "a pessoa certa no lugar certo", já hoje, em uma dimensão mais estratégica, a preocupação deixa de ser o nível micro para voltar-se para o macro da organização, cuja preocupação é extrapolar os limites de um cargo para uma estrutura organizacional mais ampla, cujo principal determinante no processo seletivo deixa de ser a qualificação e experiência anterior do candidato e predomina o potencial de desenvolvimento e suas competências individuais, buscando-se assim, profissionais sintonizados com os objetivos a longo prazo da organização (Marras, 2005). A preocupação na busca de capital humano no mercado de trabalho não pode mais ser vista e feita como era proposto no tempo em que o funcionário era contratado apenas para preencher um determinado cargo e responder somente pelas atividades pré determinadas (Pedroso \& Cintra, 2010).

Entende-se por processo seletivo o uso de procedimentos de avaliação e informações estrategicamente planejados que objetivam identificar dentre os candidatos aqueles que melhor se integrarão à cultura vigente e as expectativas (atuais e futuras) da organização (Goulart Junior, 2003). Os testes psicológicos são considerados ferramentas essenciais para a seleção de pessoal, porém este assunto levantado muitas discussões acerca de sua validade (Pereira, Primi $\&$ Corbero, 2013). Não existem testes específicos para cada profissão, portanto, não se sabe se há validade científica nessa prática (Pasqualli, 1999). Um ponto fundamental relativo à cientificidade dos instrumentos psicológicos é tratado no conceito de validade, ou seja, o alcance em que o teste mensura o que se propõe a medir ou o conhecimento do que o teste mede e de quão bem faz isso. Se um instrumento não possui evidências de validade, não há segurança de que as interpretações sobre as características psicológicas das pessoas sugeridas por suas respostas na testagem são legítimas (Primi, et. al., 2009). Em uma pesquisa realizada por Godoy e Noronha (2005) constatou-se que poucos profissionais utilizam testes nos processos seletivos e conhecem poucos instrumentos, o que pode ser justificado por variáveis como a defasagem na formação profissional, baixa qualidade psicométrica de muitos instrumentos, ausência de estudos de validade para os diferentes contextos profissionais, alto custo de alguns instrumentos, entre outros.

O profissional precisa de um conhecimento complexo que se propõe a utilizar, isso se refere em conhecer sua validade, precisão, existência de normas específicas e gerais para a população, existência de informações necessárias para aplicação, correção e interpretação dos resultados (Parpinelli \& Lunardelli, 2006). Esse é um tema de extrema importância, pois erros na contratação incorrem em injustiças com os candidatos e denigrem a imagem o papel dos psicólogos nas empresas.

Geralmente são utilizadas diversas técnicas de seleção que variam de acordo com o perfil e complexidade dos cargos e, quanto maior o número de técnica de seleção, maior será o número de informações para a seleção e maior será a chance de ter êxito na escolha (Almeida, 2009). Segundo Benucci (2003) não só a entrevista é importante no processo seletivo, mas testes psicológicos, dinâmicas de grupo entre outros, são instrumentos importantes para alcançar um maior índice de acerto nas contratações. Segundo Canisian (2002) os testes psicológicos ajudam o psicólogo a traçar o perfil do candidato, no entanto, as entrevistas e dinâmicas de grupo são instrumentos importantes e necessários, devendo fazer parte de um conjunto de informações, conferindo-lhe maior segurança na tomada das decisões. Segundo Santos et al (2003) a dinâmica de grupo por ser uma ferramenta útil para o processo de seleção, pois nessa técnica poderá ser observado padrões de comportamento compatíveis ao esperado. A seleção por competências é uma alternativa que tem-se mostrado viável, sendo possível acessar o repertório comportamental de candidatos 
(Alencar, 1996) e a dinâmica pode ser uma técnica eficaz na seleção por competências.

O processo seletivo é composto por algumas fases como atração, triagem, avaliação e decisão (Almeida, 2008). Geralmente a dinâmica de grupo antecede à etapa de entrevista, o que muitas vezes assume um caráter eliminatório, portanto, uma vez que competências não são avaliadas nessa etapa, pode-se comprometer todo o processo seletivo. Esse um motivo de grande preocupação, pois observa-se que na prática instrumentos subjetivos de avaliação, como a entrevista e dinâmica de grupo, têmsubstituído gradativamente o uso de testes psicológicos, oportunizando que qualquer profissional possa realizar a seleção (Cansian, 2002), correndo riscos de uma avaliação errônea.

A dinâmica de grupo é uma técnica vivencial bastante utilizada e tem como objetivo criar um clima descontraído, promover a interação do grupo, propiciar condições para o relacionamento interpessoal, observar atitudes frente à criatividade, iniciativa, persuasão, liderança, entre outros. É uma técnica muito interessante, sob o ponto de vista sistêmico, pois permite contato com o comportamento do indivíduo dentro de uma rede de relações com os outros candidatos, com a situação problema, os recursos, etc (Parpinelli \& Lunardelli, 2006). É uma técnica de integração de pessoas, que no contexto organizacional é considerada uma ferramenta que auxilia o processo de seleção, mas não deve ser usada isoladamente, pois não existem estudos de validade dessa técnica, uma vez que não é um teste, mas uma técnica que permite observar o candidato em uma ação, chamada de role-playing (Pereira, Primi, \& Cobero, 2003). Há estudos internacionais com jobsimulation e que demonstram uma validade maior se combinado essa técnica com medidas cognitivas (Schmidt \& Hunter, 1998), assim, novos funcionários seriam melhor selecionados se fossem utilizados dois instrumentos ao invés de um só (Pereira, Primi \& Cobero, 2003). Assim, o uso de testes e dinâmica de grupo, sucedida de entrevista pode ser um modelo eficaz nos processos seletivos.

\section{Extroversão, Introversão e $\quad$ o ambiente coorporativo.}

O desempenho no trabalho de um indivíduo, assim como em todos os comportamentos humanos, está relacionado ao ambiente em que se vive, a situação em que se está inserido e as suas características de personalidade (Ayan \& Kocacik, 2010). Atualmente o conceito mais utilizado no campo da personalidade é o modelo dos Cinco Grandes Fatores (CGF), e trata-se de uma versão moderna da Teoria de Traço que representa um avanço conceitual e empírico no campo da personalidade, descrevendo dimensões humanas básicas de forma consistente e replicável (Nunes, Hutz \& Giacomoni, 2009). No Brasil, os cinco fatores têm sido denominados Extroversão, Socialização (também chamado por alguns autores por Amabilidade), Realização (também denominado Conscienciosidade), Neuroticismo e Abertura (Hutz \& cols., 1998; Nunes, \& Hutz, 2002). Neste modelo, a Extroversão estárelacionado as formas como as pessoas interagem com os demais e indica o quão comunicativas, falantes, ativas, assertivas, responsivas e gregárias elas são. Já os introvertidos tendem a ser reservados, sóbrios, indiferentes, independentes e quietos. Introvertidos não são necessariamente pessoas infelizes ou pessimistas, mas não são dados aos estados de espírito exuberantes que caracterizam os extrovertidos (Nunes \& Hutz, 2006).

Certamente no universo corporativo competências como Comunicação e Extroversão são requeridas, importantes e necessárias e, segundo Costa (2015) as empresas buscam pessoas com um determinado estilo, considerando fatores como: a assertividade, as habilidades de oratória, a expressão corporal, assim como se posicionar a frente, características estas marcantes no estilo extrovertido. No contexto do trabalho e das organizações, extroversão têm se mostrado uma importante variável, que se relaciona e prediz construtos úteis na área (Salgado, 2002). Porém deve-se considerar as potencialidades do perfil introvertido que são marcadas pelo lado humanístico, valorizando as pessoas acima de qualquer coisa, são ótimos ouvintes, dominam como ninguém a habilidade de se manter calmo, equilibrado e tranquilo em momentos de estresse, sabendo planejar suas ações para tomar iniciativa no momento certo (Costa, 2015). Desta forma, é importante entender com clareza quais serão as atribuições requeridas ao cargo e não subestimar o 
perfil introvertido, evitando relacionar o perfil psicológico com o desempenho no trabalho.

Em uma pesquisa realizada por uma empresa norte americana de testes de personalidade e carreira, os extrovertidos tem maior sucesso profissional, ou seja, as remunerações médias das pessoas extrovertidas podem chegar a $\$ 77 \mathrm{mil}$ dólares por ano, enquanto os introvertidos ganham uma média de $\$ 59$ mil dólares por ano (Lebowitz, 2015). Segundo Cain (2013) mesmo que os introvertidos estejam mais preparados e tenham melhores resultados, rotineiramente os extrovertidos é que são escolhidos para posições de liderança, pois as pessoas entendem que os extrovertidos são líderes mais eficazes simplesmente porque falam mais e melhor.

Mills (2005) entende que os introvertidos podem perfeitamente tornar-se bons lideres já que possuem qualidades importantes como a capacidade para escutar, para avaliar problemas a fundo e um censo acurado para a observação. Collins (2002) realizou um estudo com líderes e identificou que os CEOs que não são tão conhecidos por sua imagem carismática (introvertidos) vêm gerando mais retorno na bolsa de valores que seus colegas mais chamativos (extrovertidos).

Assim, é necessário entender essa temática no contexto atual, rompendo alguns paradigmas e superando alguns preconceitos, afim de não prejudicar e subestimar grandes potenciais em função de características intrapessoais de personalidade.

\section{A Dinâmica de grupo como uma possibilidade para avaliação da criatividade}

Uma prática bastante frequente para avaliação de competências nas empresas é a Entrevista e a Dinâmica de Grupo (Pedroso \& Cintra, 2010; Andrade, 2009; Godoy \& Noronha, 2005; Pereira, Primi, \& Cobêro, 2003; Santos, Franco, \& Miguel, 2003). Em estudo realizado com Psicólogos que atuam na área organizacional nos recursos humanos, constatou-se que a grande maioria destes profissionais já precisaram avaliar a criatividade, porém apenas $6 \%$ utiliza algum instrumento psicológico para completar esta avaliação. Na prática, a entrevista e a dinâmica de grupo são as principais estratégias para avaliar a criatividade (Nalevaiko-Rocha \& Wechsler, no prelo). Assim, é possível sugerir que não apenas há um desconhecimento dos profissionais em relação aos instrumentos de avaliação, como também, segundo Garcês, et al (2014) ainda existem poucas ferramentas para avaliar a criatividade, mesmo que o interesse pelo tema tenha ganhado maior importância e destaque.

A dinâmica de grupo é uma técnica que permite observar o candidato diante de uma ação real. Geralmente o avaliador propõem uma situação-problema e os candidatos em grupo devem procurar soluções. A avaliação se dá através da observação do avaliador dos comportamentos apresentados durante a dinâmica (Pedroso \& Cintra, 2010). Sabe-se que a criatividade envolve a definição e redefinição de problemas (Sternberg \& Lubart, 1991), e pessoas criativas teriam uma capacidade maior em identificar elementos faltantes, falhas e deficiências em situações para então formular novas hipóteses e propor novas soluções (Torrance, 1965). Assim, a dinâmica de grupo poderia ser considerada uma possibilidade de avaliação da criatividade por envolver situações de resoluções de problemas com um caráter avaliativo.

No entanto, não há estudos de validade sobre a dinâmica de grupo, o que incorre a uma avaliação baseada na subjetividade, não demostrando atender a critérios científicos necessários (Pereira, Primi, \& Cobêro, 2003). Assim, maiores estudos que analisem se há validade desta técnica para a avaliação da criatividade podem trazer grandes benefícios e são de extrema importância para embasar com maior consistência a atuação do psicólogo nos processos seletivos, contribuindo para o entendimento do fenômeno criativo, suas formas de expressão e mostrando-se como mais uma possibilidade avaliativa. Desta forma, o objetivo principal deste trabalho foi comparar a avaliação da criatividade por testes com a Dinâmica de Grupo em processos seletivos nas organizações. Teve como objetivo específico analisar os critérios de julgamento para avaliação da criatividade.

\section{Método}

\section{Participantes}

A amostra foi composta por 54 sujeitos, sendo 52 candidatos a processos seletivos e 2 
Avaliadoras. Os candidatos, 16 candidatos do sexo feminino e 36 candidatos do sexo masculino, eram participantes de processos seletivos para vagas em estágio de empresas nos estados de São Paulo, sendo 44 candidatos desta região e 8 candidatos do Paraná. Dos candidatos participantes, 43 são da área de Exatas e 9 da área das Ciências Humanas. As idades variaram de 18 a 37 anos, a média das idades foi de 23,21 e o desvio padrão foi de 3,59. Em relação às 2 avaliadoras, 1 é do estado de São Paulo e 1 do estado do Paraná. Ambas têm formação em Psicologia, Pós-Graduação e experiência na área de seleção de pessoas de pelo menos 5 anos. $\mathrm{O}$ critério de inclusão foi a aceitação de participação na pesquisa, mediante Termo de Consentimento Livre e Esclarecido.

\section{Instrumentos}

\section{Testes de Torrance $\mathrm{e}$ validação para a realidade brasileira}

Torrance (1966) desenvolveu os testes de pensamento criativo em suas formas verbal e figural. Inicialmente, baseou-se apenas em 4 dimensões para avaliar a criatividade, são elas: fluência, flexibilidade, originalidade e elaboração. Ele conseguiu demonstrar a validade de construto das mesmas, relacionando-as com produções de crianças e avaliação de seus professores, porém, entendia que havia limitação destas medidas. Posteriormente, realizou estudos longitudinais acompanhando sujeitos que responderam a seu teste em 1958 para avaliar a sua produção criativa após 14 anos, depois após 23 anos e finalmente após 30 anos da primeira aplicação dos testes. Estes estudos de importante magnitude, comprovaram a validade preditiva de seus testes, demonstrando que existiam relações significativas entre vários indicadores da criatividade figurativa nos seus testes com a quantidade e a qualidade da produção na vida real dos indivíduos, provando assim, que a criatividade poderia ser medida de maneira precisa (Torrance, 1972, 1981, 1992).

O estudo de investigação de evidências de validade dos Testes de Torrance na realidade brasileira foi realizado com uma amostra de 128 sujeitos, sendo 59 definidos como criativos e 69 considerados como não criativos ou regulares. $\mathrm{O}$ critério para classificação como indivíduo criativo foi o de ter sua produção reconhecida na vida real, aferida por meio de prêmios e distinções recebidas. Esse foi o mesmo critério utilizado por Torrance em seus estudos longitudinais em 1981. Através da correlação de Pearson, comparou-se cada característica criativa com o total de pontos recebidos pela produção reconhecida, não reconhecida e o total. Através do Teste T buscouse avaliar se os resultados nos testes poderiam indicar e discriminar o grupo criativo do não criativo. Após, comparou-se e correlacionou-se o resultado dos 2 testes afim de investigar se ambos medem o mesmo construto. Os resultados indicaram altas correlações entre os resultados dos testes verbais e figurais e a produção reconhecida na vida real $(p<.001)$.

\section{Folha de Observação da Dinâmica}

Foi elaborado uma Folha de Observação nesta pesquisa com o objetivo de permitir que o avaliador preenchesse suas observações e pudesse ser interpretado os critérios e sua avaliação sobre a criatividade de cada candidato. Esta folha de observação era preenchida pelo Avaliador e composta por: cargo, nome do candidato, idade, sexo, escolaridade e avaliação da criatividade. A avaliação da criatividade era dada através de uma nota de 0 a 10 considerando 0 não criativo e 10 muito criativo. $\mathrm{O}$ próximo campo pedia a justificativa da nota e os critérios que utilizou e julgou ser importante para avaliar a criatividade de cada candidato. São questões fechadas que consideram: personalidade, inteligência, comunicação, qualidade de ideias, persuasão ou outros aspectos, com espaço para outras anotações.

\section{Procedimento}

A pesquisa foi submetida ao Comitê de Ética em Pesquisa da Pontifícia Universidade Católica de Campinas e realizada em empresas de Consultoria de Recursos Humanos nos Estado do Paraná e São Paulo. Foi explicado às empresas que os dados obtidos na pesquisa não seriam disponibilizados e não deveriam influenciar na avaliação do Processo seletivo. Explicou-se também que elas deveriam aplicar a dinâmica e conduzir o processo seletivo da forma como elas desejassem, não houve portanto, nenhuma interferência da pesquisadora em relação às 
atividades e forma de avaliação. Em relação aos candidatos participantes de processo seletivo foi realizado o convite para participação na pesquisa somente após a participação do sujeito na dinâmica de grupo. Foi exposto aos candidatos que a pesquisa é de caráter anônimo, voluntário e totalmente independente do processo de seleção, assim, não deveria haver nenhum constrangimento em negar o convite para participar da pesquisa e não houve nenhum vínculo com $o$ seu desempenho ou avaliação no processo seletivo. Ao término da dinâmica foi aplicado os Testes de Torrance. A ordem de aplicação dos testes foi alternada entre as turmas. Visando viabilizar e tornar possível a aplicação da pesquisa nestas condições, alterou-se o tempo de aplicação dos testes, sendo 5 minutos para as atividades 1 , 4 e 6 dos Testes Pensando Criativamente com Palavras e 10 minutos para a atividade 2 do Teste Pensando Criativamente com Figuras.

Durante a realização da Dinâmica de Grupo as Avaliadoras transitavam entre os candidatos enquanto observavam a participação de cada um. Como a dinâmica previa a resolução de um problema, as mesmas buscavam identificar comportamentos relevantes e preenchiam o Formulário de Avaliação da Criatividade, considerando aspectos que atribuíam a comportamentos criativos nos candidatos. Atribuiu-se uma nota de 0 a 10 e considerou-se as observações que justificavam esta nota.

\section{Resultados}

Este estudo teve como objetivo principal comparar a avaliação da criatividade por testes com a Dinâmica de Grupo em processos seletivos. Embasou-se na hipótese de que avaliação da criatividade sem a aplicação de instrumentos psicológicos de avaliação é ineficaz e beneficia candidatos mais extrovertidos e comunicativos, trazendo prejuízos ao processo seletivo.

O Quadro 1 considera os critérios utilizados para avaliação da criatividade nos candidatos e descreve as informações analisadas do material de observação da Dinâmica de Grupo (Folha de Observação da DG da pesquisa ou da Consultoria) preenchidas pelas Avaliadoras. Aqui as observações descritas foram categorizadas em conteúdos gerais à partir dos adjetivos empregados.

Quadro 1. Classificação dos temas dos Avaliadores

\begin{tabular}{|c|c|}
\hline $\begin{array}{l}\text { Classificação } \\
\text { Temas } \\
\end{array}$ & Adjetivos \\
\hline $\begin{array}{l}\text { Personalidade } \\
\text { Extrovertida }\end{array}$ & $\begin{array}{l}\text { Despojado, extrovertido, simpático, boa } \\
\text { desenvoltura, desinibido. }\end{array}$ \\
\hline $\begin{array}{l}\text { Personalidade } \\
\text { Introvertida }\end{array}$ & Tímido, mais observador, mais ouvinte. \\
\hline $\begin{array}{l}\text { Comunicação } \\
\text { Positiva }\end{array}$ & $\begin{array}{l}\text { Comunicativo, fala bem, expressa-se } \\
\text { bem, boa fluência verbal, conversa bem, } \\
\text { seguro para falar. }\end{array}$ \\
\hline $\begin{array}{l}\text { Comunicação } \\
\text { Negativa }\end{array}$ & Quieto, não fala nada. \\
\hline Liderança & $\begin{array}{l}\text { Conduz o grupo, perfil de liderança, } \\
\text { ideias são aceitas pelo grupo. }\end{array}$ \\
\hline $\begin{array}{l}\text { Qualidade e } \\
\text { Quantidade de } \\
\text { Ideias }\end{array}$ & $\begin{array}{c}\text { Coloca ideias, sugere soluções, dá várias } \\
\text { ideias, participa com muitas ideias, soube } \\
\text { colocar pontos importantes e deu ideias, } \\
\text { explorou pontos importantes, deu } \\
\text { sugestões. }\end{array}$ \\
\hline
\end{tabular}

Quadro 2. Frequência nota de criatividade pelos avaliadores

\begin{tabular}{lccc}
\hline Nota & Frequência & Porcentual & $\begin{array}{c}\text { Porcentagem } \\
\text { válida }\end{array}$ \\
\hline 2 & 2 & 3.8 & 3.8 \\
3 & 1 & 1.9 & 1.9 \\
4 & 4 & 7.7 & 7.7 \\
5 & 9 & 17.3 & 17.3 \\
6 & 6 & 11.5 & 11.5 \\
7 & 11 & 21.2 & 21.2 \\
8 & 12 & 23.1 & 23.1 \\
9 & 6 & 11.5 & 11.5 \\
10 & 1 & 1.9 & 1.9 \\
Total & 52 & 100.0 & 100.0 \\
\hline
\end{tabular}

O Quadro 2 indica que de forma geral a as notas mais frequentes foram 7 e 8 . Apenas $1.9 \%$ tiveram nota 10 , ou seja, uma avaliação pouco discriminativa.

O Quadro 3 apresenta a correlação de Pearson dos critérios utilizados pelos avaliadores e as dimensões avaliadas no Teste Pensando Criativamente com Palavras e Figuras de Torrance: fluência, elaboração, originalidade e títulos expressivos.

O Quadro 3 nos permite analisar que não há nenhuma correlação com os critérios e notas atribuídas à criatividade de cada candidato com nenhuma das dimensões avaliadas no teste de Torrance Figural ou Verbal . Em vários casos ainda, essa correlação é negativa. 
Quadro 3. Correlação de Pearson dos critérios utilizados pelos avaliadores e as dimensões do Teste de Torrance

\begin{tabular}{lccccccc}
\hline & TOFluVerb & TOElaVerb & TOOriVerb & TOFigFlu & TOFigEla & TOFigOri & ToFigTit \\
\hline Nota & .012 & -.099 & -.086 & -.179 & -.265 & .067 & .198 \\
Int & -.166 & -.050 & -.054 & .078 & .173 & -.269 & .010 \\
Ext & .180 & .064 & .095 & .022 & -.150 & .287 & -.048 \\
Com & .266 & .042 & .190 & .093 & -.290 & .223 & .125 \\
QQI & .253 & .279 & .329 & -.166 & .116 & -.103 & -.059 \\
\hline$p<.05$ & $* * p<.01$ Intro-Introversão & Extro-Extroversão & Comun-Comunicação & QQId-Quantidade e Qualidade
\end{tabular}

de Idéias TO-Torrance Verb-Verbal Fig- Figural Flu-Fluência Ela-Elaboração Ori-Originalidade Tit-Títulos Expressivos

Quadro 4. Correlação de Pearson dos critérios utilizados pelos avaliadores para criatividade

\begin{tabular}{lcccc}
\hline & Introversão & Extroversão & Comunicação & QualieQuantiIdeias \\
\hline Notacriatividade & $-.751^{* *}$ & $.684^{* *}$ & $.700^{* *}$ & $.414^{*}$ \\
Introversão & 1 & $-1.000^{* *}$ & $-.811^{* *}$ & -.431 \\
Extroversão & $-1.000^{* *}$ & 1 & $.744^{* *}$ & $.516^{*}$ \\
Comunicação & $-.811^{* *}$ & $.744^{* *}$ & 1 & .397 \\
QualieQuantiIdeias & -.431 & $.516^{*}$ & .397 & 1 \\
\hline$p^{*}<.05 \quad * * p<.01$ & & & &
\end{tabular}

O Quadro 4 nos permite analisar a correlação entre a nota e os critérios utilizados pelos avaliadores para avaliação da criatividade dos candidatos.

O Quadro 4 nos permite uma análise que correlaciona a nota dada pelo avaliador em relação a criatividade observada na dinâmica e os critérios citados para compor esta avaliação. As notas correlacionam-se com as dimensões extroversão, comunicação e qualidades de idéias. A introversão está negativamente relacionada com as notas.

\section{Discussão e Conclusões}

O objetivo principal deste trabalho foi comparar a avaliação da criatividade através de testes com a Dinâmica de Grupo em processos seletivos. Este estudo pretendeu responder a principal inquietação que motivou esta pesquisa: Como a criatividade é avaliada nas empresas? Há eficácia nas técnicas empregadas?

Ao início deste estudo esperava-se que os critérios adotados nas empresas são diferentes dos critérios teóricos e acadêmicos. Os resultados desta pesquisa confirmam esta hipótese mostrando que não há nenhuma relação entre as dimensões avaliadas nos testes e a nota dada pelo avaliador referente à criatividade do candidato.

Os critérios utilizados pelos avaliadores para compor a avaliação de cada candidato foram mensurados através da análise de conteúdo das anotações realizada pelos avaliadores e dos critérios preenchidos por eles na Folha de Observação da Dinâmica de Grupo. Estes critérios foram: comunicação, extroversão ou introversão, liderança, qualidade e quantidade de ideias e participação no grupo. Porém, os demais os critérios utilizados pelas empresas para avaliar a criatividade dos candidatos: Introversão, Extroversão, Comunicação e Qualidade de ideias não se relacionam com as dimensões fluência, elaboração e originalidade avaliadas no Teste Pensando Criativamente com Palavra - TPCP e o Teste Pensando Criativamente com Figuras TPCF, fluência, elaboração, originalidade e títulos expressivos. Desta forma, pode-se concluir que os critérios utilizados pelas empresas para avaliar a criatividade são diferentes das dimensões avaliadas nos testes formais de avaliação da criatividade.

A relação entre os critérios utilizados pelos avaliadores e a nota dada em criatividade levanta um dado importante. As notas relacionaram-se positivamente com as dimensões comunicação, extroversão e qualidade e quantidade de ideias, nesta ordem de significância. Esse dado nos aponta que características intrapessoais e de temperamento parecem estar mais relacionadas com a avaliação da criatividade nas empresas, ou seja, pessoas mais extrovertidas e comunicativas 
são vistas como mais criativas e são melhores avaliadas nos processos seletivos.

Certamente no universo corporativo competências como Comunicação e Extroversão são requeridas, importantes e necessárias e, segundo Costa (2015) as empresas buscam pessoas com um determinado estilo de liderança, considerando fatores como: a assertividade, as habilidades de oratória, a expressão corporal, assim como se posicionar a frente, características estas marcantes no estilo extrovertido. No contexto do trabalho e das organizações, extroversão têm se mostrado uma importante variável, que se relaciona e prediz construtos úteis na área (Salgado, 2002).

No entanto, é importante considerar as potencialidades do perfil introvertido, e mesmo que a liderança introvertida ainda é inexpressiva nas organizações, este perfil agrega características importantes para várias áreas da organização e traz resultados expressivos (Costa, 2015). Desta forma, é importante entender com clareza quais serão as atribuições requeridas ao cargo e não subestimar o perfil introvertido, evitando relacionar o temperamento dos candidatos com o desempenho no trabalho.Assim, é necessário entender essa temática no contexto atual, romper alguns paradigmas e superar alguns preconceitos, afim de não prejudicar e subestimar grandes potenciais em função de características intrapessoais de personalidade.

Desta forma, a ausência de um teste científico que avalie a criatividade pode estar deixando de avaliar o potencial criativo de pessoas que não extrovertidas, ou seja, as empresas podem perder grandes potenciais criativos baseando-se apenas na observação e na avaliação subjetiva. Estudos realizados por Nalevaiko-Rocha \& Wechsler (2015) indicam que a maioria dos psicólogos que atuam na área de Recursos Humanos não utilizam nenhum instrumento para avaliar a criatividade nas empresas, prevalecendo técnicas de entrevista e observação, que podem conferir uma avaliação baseada na subjetividade e relacionada a aspectos do temperamento dos candidatos. Desta forma, é de extrema importância que instrumentos científicos validados sejam incorporados aos processos seletivos. Segundo Pallás \& Lloréns (2010) estudos na área de avaliação psicológica que considerem aspectos da personalidade começam a assumir predominância neste campo de investigação, apontando e reforçando a importância de instrumentos que avaliem dimensões da personalidade e apóiem de maneira efetiva o trabalho dos profissionais em diversos contextos.

Há estudos internacionais com job simulation e que demonstram uma validade maior se combinado essa técnica com medidas cognitivas (Schmidt \& Hunter, 1998). Assim sendo, novos funcionários seriam melhor selecionados se fossem utilizados mais de um instrumento ao invés de um só (Pereira, Primi \& Cobero, 2003). Assim, o uso de testes pode ser combinado a outras técnicas como a entrevista e dinâmica de grupo, sendo este um modelo mais eficaz nos processos seletivos.

Concluindo, este trabalho demonstra a importância de utilizar-se testes estandardizados para garantir a eficácia dos processos seletivos, buscando eximir o quanto for possível aspectos subjetivos na avaliação, desta forma, evitando uma avaliação baseada apenas na observação e contribuindo para um resultado mais científico e confiável. Este estudo teve como foco a avaliação da criatividade, e concluiu-se que a avaliação realizada através da observação em dinâmica não é eficaz. Não há correlação entre as notas atribuídas pelas avaliadoras e com o total dos testes de Torrance através das dimensões criativas que são avaliadas.

\section{Limitações, estudos e direções futuras.}

Uma das principais limitações deste estudo foi em relação ao tamanho e composição da amostra, esperava-se aproximadamente 6 avaliadores, afim de conseguir mais dados relativos as concepções de criatividade e critérios de avaliação. Neste estudo participaram apenas 2 avaliadores. $\mathrm{O}$ número de candidatos também pode ser maior, compondo uma amostra mais expressiva. Desta forma, futuros estudos poderiam contemplar uma amostra maior e um número maior de avaliadores.

Estima-se que futuros estudos contribuirão com a área de avaliação psicológica nas empresas, demonstrando a importância da utilização de testes nos processos seletivos e fomentando a criação de novos testes estandardizados e validados no Brasil que possam apoiar com maior 
eficácia o trabalho dos psicólogos na área de Recursos Humanos.

\section{Referências}

Alencar, E. M. L. S., \& Fleith, D.S. (2003). Criatividade: Múltiplas perspectivas. Brasília: UnB.

Alencar, E.M.L.S. (1995). Desenvolvendo a criatividade nas organizações: O desafio da inovação. Revista de Administração de Empresas, 35(6), 6-11.

Almeida, W. (2008) Captação e seleção de talentos: Repensando a teoria e a prática. São Paulo: Atlas.

Amabile, T. M. (2001). Beyond talent: John Irving and the passionate craft of creativity. American Psychologist, 56(4), 333-336.

Andrade, K. M. (2009). Práticas de recrutamento e seleção nas empresas. Psicologia IESB, 10(10), 1-10.

Ayan, S., \& Kocacik, F. (2010). The relation between the level of job satisfaction and types of personality in high school teachers. Australian Journal of Teacher Education, 35(1), 27-41. doi: 10.14221/ajte.2010v35n1.4

Bates, S. (2001) Study links HR practices with the bottom-line. HR Magazine, 46(12), 14-27.

Bedani, M. (2008). Valores, práticas e criatividade organizacionais: Estudo do perfil cultural de uma instituição bancária. Tese de Doutorado, Universidade de Brasília, Brasília, DF, Brasil.

Benucci, M. (2003). Entrevista e processo seletivo. Recuperado em 29 de abril de 2015 de http://www.rh.com.br/.

Bruno-Faria, M. F. (2003). Criatividade, inovação e mudança organizacional. In S.M.V. Lima (Org). Mudança Organizacional: teoria $e$ gestão. (pp.111-142). Rio de Janeiro: FGV.

Cain, S. (2012) O poder dos quietos: Como os tímidos e introvertidos podem mudar o mundo que não para de falar (Ribeiro, A.C.B., Trad.). Rio de Janeiro: Agir. (Obra original publicada em 2013).

Campos, K. C. L, Duarte, C., Cezar, E. O., \& Pereira, G. O. A. (2011). Psicologia organizacional e do trabalho - Retrato da produção científica na última década.
Psicologia Ciência e Profissão, 31(4), 702717.

Canisian, R. M. M. (2002). O psicólogo e seu espaço nas organizações. Recuperado em 30 de maio de 2015, de http://www.cjh.ufsc.br/sinapsi/artigos/organiz acional3htm.

Costa, P. H. F. C. (2015). Liderança: Dificuldades e potencialidades de um líder introvertido nas organizações. ENIAC Pesquisa, 4(1), 81-98.

Garcês, S., Pocinho, M., De Jesus, S. N., Viseu, J. Imaginário, S., \& Wechsler, S. M. (2014). Estudo de validação da escala de Personalidade Criativa. Revista Iberoamericana de Diagnóstico y Evaluación - e Avaliação Psicológica, 40(2), 17 -24.

Godoy, S. L., \& Noronha, A. P. P. (2005). Instrumentos psicológicos utilizados em seleção profissional. Revista do Departamento de Psicologia UFF, 17(1), 139-159.

Goulart Junior, E. (2003). Avaliação psicológica em processos seletivos: Uma análise da atuação do psicólogo em consultorias de recursos humanos da cidade de Bauru. (pp.171). Texto mimeografado.

Hutz, C. S., Nunes, C. H. S. S., Silveira, A. D., Serra, J., Anton, M., \& Wieczorek, L. S. (1998). O desenvolvimento de marcadores para a avaliação da personalidade nos modelos dos Cinco Grandes Fatores. Psicologia: Reflexão e Crítica, 11(2), 395409.

Jiménes-Jiménez, D., \& Sanz-Valle, R. (2005). Innovation and human resource fit: An empirical study. International Journal of Manpower, 36(4), 364-398.

Milaré, S. A., \& Yoshida, E. M. P. (2007). Coaching de executivos: Adaptação e estágio de mudanças. Psicologia: Teoria e Prática, 9(1), 86-99.

Mills, D.Q. (2005). Principles of Management. USA: KindleEdition.

Nalevaiko-Rocha, K., \& Wechsler, S.M. (2016). A criatividade nas organizações: Da concepção às formas de avaliação. Revista de Carreiras e Pessoas, 6(3), 248-261.

Neto, A.M.C., Tanure, B., \& Andrade, J. (2010). Executivas: Carreira, maternidade, amores e preconceitos. Revista de Administração Eletrônica, 9(1), 17-33. 
Noronha. A. P. P. (2002). Os problemas mais graves e mais frequentes no uso dos testes psicológicos. Psicologia: Reflexão e crítica, 15(1), 135-142.

Nunes, C. H. S. S., \& Hutz, C. S. (2002). O modelo dos Cinco Grandes Fatores de Personalidade. In R. Primi (Org.). Temas em Avaliação Psicológica, (pp. 40-49). Campinas, IBAP.

Nunes, C. H., Hutz, C. S., \& Giacomini, C. H. (2009) Associação entre bem-estar subjetivo e personalidade no modelo dos cinco grandes fatores. Revista Avaliação Psicológica, 8(1), 99-108.

Oakland, T. (1996). Qualities that will influence testing and assessment practices with children and youth toward the beginning of the twentyfirst century. Psicologia Escolar $e$ Educacional, 1(1), 1-15.

Pallás, C., \& Llorens, O. (2010). Enfoque de la evaluación psicológica de la Revista Iberoamericana de Diganóstico y Evaluación Psicológica (Ridep). Revista Iberoamericana de Diagnóstico y Evaluación - e Avaliação Psicológica, 2(30), 35 - 56.

Parpinelli, R. F., \& Lunardelli, M. C. F. (2006). Avaliação psicológica em processos seletivos: Contribuições da abordagem sistêmica. Estudos de Psicologia, 23(4), 463-471.

Pasqualli, L. (1999). Instrumentos psicológicos: Manual prático de elaboração. Brasília: LabPAM.

Paulino, M. L. S. (2010). Dimensão estratégica do recrutamento e seleção de pessoal. Administração de Empresas em Revista, 9(10), 95- 109.

Pedroso, R., \& Cintra, G. A. (2010). Seleção de pessoal: Influências dos comportamentos emocionais e seleção de repertório comportamental. Revista Olhar Científico, $1(1), 12-32$.

Perdomo-Ortiz, J., González-Benito, J., \& Galende, J. (2009). An analysis of the relationship between total quality management-based human resource management practices and innovation. The international Journal of Human Resource Management, 20(5), 1191-1218.

Pereira, F. M., Primi, R., \& Cobero, C. (2003). Validade de testes utilizados em seleção de pessoal segundo recrutadores. Revista Teoria e Prática, 5(2), 83-98

Primi, R. (2010). Avaliação psicológica no Brasil: Fundamentos, situação atual e direções para o futuro. Psicologia: Teoria e Pesquisa, 26(1), 25-35.

Primi, R., Muniz, M., \& Nunes, C. H. S. S. (2009). Definições contemporâneas de validade de testes psicológicos. In C.S. Hutz (Org). Avanços e polêmicas em avaliação psicológica (pp 243-265). São Paulo: Casa do Psicólogo.

Rodrigues, A. F., \& Veloso, A. (2013). Contribuições da gestão de recursos humanos para a criatividade e inovação organizacional. Revista Psicologia: Organizações e Trabalho, 13(3), 293-308.

Salgado, J. F. (2002). The big five personality dimensions and counterproductive behaviors. International Journal of Selection and Assessment, 10(1), 117-125

Schmidt, F. L., \& Hunter, I. E. (1998). The validity and utility os selection methods in personnel psychology: Practical and theoretical implications of 85 years of research findings. Psychology Bulletin, 124, (pp 262-274).

Shipton, H., West, M. A., Dawson, J. Birdi, K., \& Patterson, M. (2006) HRM as a predictor of innovation. Human Resource Management Journal, 16(1), 3-27.

Tachizawa T. (2001). Gestão com pessoas: Uma abordagem aplicada às estratégias de negócio. Rio de Janeiro: FGV.

Ulrich, D. (1998). Os campeões de recursos humanos - inovando para obter os melhores resultados. São Paulo: Futura.

Zacharias, J. J. M. (2006). Tipos: A diversidade humana. São Paulo: Vetor. 